continue for several years with different epidemiological features. The selection and number of controls is of utmost importance. In an optimal study, both healthy controls and controls with non-pneumonic respiratory infections matched for age and sex from the same area should be considered. Genetic epidemiology offers the frame of reference for such studies.

\section{T. Heiskanen-Kosma* and M. Korppi ${ }^{\#}$}

*Dept of Paediatrics, Kuopio University Hospital, Kuopio, and "Paediatric Research Center, Tampere University and University Hospital, Tampere, Finland.

Correspondence: M. Korppi, Paediatric Research Center, Tampere University and University Hospital, FM-3 building, 33014 Tampere, Finland. E-mail: matti.korppi@uta.fi

\section{REFERENCES}

1 Teepe J, Grigoryan L, Verheij TJM. Determinants of communityacquired pneumonia in children and young adults in primary care. Eur Respir J 2010; 35: 1113-1117.

2 Jokinen C, Heiskanen L, Juvonen $\mathrm{H}$, et al. Incidence of communityacquired pneumonia in the population of four municipalities in eastern Finland. Am J Epidemiol 1993; 137: 977-988.

3 Heiskanen-Kosma T, Korppi M, Jokinen C, et al. Etiology of childhood pneumonia: serologic results of a prospective, population-based study. Pediatr Infec Dis J 1998; 17: 986-991.

4 Heiskanen-Kosma T, Korppi M, Jokinen C, et al. Risk factors for community-acquired pneumonia: A population-based case-control study. Scand J Infect Dis 1997; 29: 281-285.

5 Korppi M, Heiskanen-Kosma T, Kleemola M. Incidence of community-acquired pneumonia in children caused by Mycoplasma pneumoniae: Serological results of a prospective, population-based study in primary health care. Respirol 2004; 9: 109-114.

\title{
Vital capacity in lying position: important in Duchenne patients
}

\section{To the Editors:}

It was with great interest that we read the paper of LO MAURO et al. [1] entitled "Abdominal volume contribution to tidal volume as an early indicator of respiratory impairment in Duchenne muscular dystrophy" in a recent issue of the European Respiratory Journal. This paper very elegantly explained the contribution of the abdominal volume to tidal volume if patients with Duchenne disease are getting older and change from sitting to supine position. Especially in figure 6 of that manuscript, one can see very clearly the different contribution of ribcage and abdomen (diaphragm) if the patient is getting older. Despite the important contribution of this paper in this field, we would like to make two comments.

First, while the kinematic analysis was performed in both sitting and supine position, the pulmonary function tests were performed in sitting position only. This is a pity, as we know that a drop in vital capacity (VC), when a patient goes from sitting to supine position, is a sign of diaphragm paralysis. In contrast to optoelectronic plethysmography, spirometry in both positions is a simple test that can be performed in every hospital. Therefore, it would be interesting to know if the drop in the VC shows the same pattern in the different patients used in this study. For a physician taking care of these patients, it would be important to know whether he can rely on the VC in different positions to know whether the diaphragm is impaired or not.

Secondly, in this paper the assessment of nocturnal hypoxaemia is presented as clinically relevant and seems to be more pronounced in the patients with a smaller change in abdominal volume. While this might be true, the point of nocturnal hypoventilation is missed in the discussion. It was shown in the paper by WARD et al. [2] that nocturnal hypoventilation, with normocapnia during daytime, is an important indicator of respiratory impairment. They showed that even in these patients chronic ventilation is of benefit and should be started at this moment. Therefore the paper could have been even more informative if data on nocturnal carbon dioxide were included.

\section{P. Wijkstra, A. Hazenberg and J. Nieuwenhuis}

Dept of Pulmonary Diseases, University Medical Centre Groningen, Groningen, The Netherlands.

Correspondence: P. Wijkstra, Dept of Pulmonary Diseases, University Medical Centre Groningen, Hanzeplein 1, 9700 RB Groningen, The Netherlands. E-mail: p.j.wijkstra@int.umcg.nl

Statement of Interest: None declared.

\section{REFERENCES}

1 Lo Mauro A, D'Angelo MG, Romei M, et al. Abdominal volume contribution to tidal volume as an early indicator of respiratory impairment in Duchenne muscular dystrophy. Eur Respir J 2010; 35: 1118-1125.

2 Ward S, Chatwin M, Heather S, et al. Randomised controlled trial of non-invasive ventilation (NIV) for nocturnal hypoventilation in neuromuscular and chest wall disease patients with daytime normocapnia. Thorax 2005; 60: 1019-1024. 